\title{
Lymphedema in survivors of breast cancer (Review)
}

\author{
LIN HE*, HUILI QU*, QIAN WU and YUHUA SONG \\ Breast Center B Ward, The Affiliated Hospital of Qingdao University, Qingdao, Shandong 266000, P.R. China
}

Received June 29, 2019; Accepted November 7, 2019

DOI: $10.3892 / 01.2020 .11307$

\begin{abstract}
The tremendous improvement of survival in patients with breast cancer can be attributed to several treatment strategies, but these strategies also lead to the occurrence of breast cancer-related lymphedema (BCRL). BRCL is regularly associated with factors such as axillary lymph node dissection and local lymph node radiotherapy and manifests as an increase of $>10 \%$ in the volume of affected limbs. Being overweight or having obesity (body mass index $\geq 25 \mathrm{~kg} / \mathrm{m}^{2}$ ), an excessive number of positive lymph nodes $(>8)$ and capsular invasion by a tumor are additional risk factors for lymphedema. It is worth assessing the risk before surgery as this can prevent the occurrence of BCRL at the initial stage of breast cancer management. The clinical utility of many diagnostic tools and lymphedema surveillance allows early stage and even subclinical BCRL to be diagnosed, and allows real-time monitoring of the disease. The early diagnosis of BRCL allows treatment at an early stage, which is beneficial to the reduction of excess limb volume and the improvement of quality of life. At present, the major therapeutic methods of BCRL include complex decongestive therapy, pneumatic compression devices, participating in exercise, microsurgery and liposuction, each of which alleviates lymphedema effectively. No medications for treatment of BRCL have yet been developed. However, the recent findings on the success of molecular therapy in animal models may remedy this deficiency. Furthermore, the volume reduction of swollen limbs without swelling rebound by transplanting autologous stem cells has been successfully reported in some pilot studies, which may provide a new technique for treating BCRL. This review aimed to discuss the pathogenesis, clinical manifestation, risk factors, advantages and disadvantages of diagnostic tools, lymphedema surveillance and the characteristics of traditional and newly emerging BCRL treatments.
\end{abstract}

Correspondence to: Dr Yuhua Song, Breast Center B Ward, The Affiliated Hospital of Qingdao University, 59 Haier Road, Laoshan, Qingdao, Shandong 266000, P.R. China

E-mail: qdsongyh@126.com

${ }^{*}$ Contributed equally

Key words: lymphedema, swelling, breast cancer

\section{Contents}

1. Introduction

2. Pathogenesis

3. Risk factors

4. Prevention

5. Diagnosis and surveillance

6. Treatment

7. Conclusions

\section{Introduction}

Survival improvement in breast cancer has been attained using surgical treatment, radiotherapy and targeted therapy, however, patients experience discomfort related to treatment related complications including breast cancer-related lymphedema (BCRL) (1). The first common consequence of trauma, infection, surgery or irradiation injury is BCRL, especially in lymphadenectomy, and this manifests as regionalized damage to the normal vasculature and an increase in limb volume by $\geq 10 \%$ (2). BCRL severely affects the quality of life of patients due to lifestyle and occupational alterations, changes in functional status, as well as changes in psychosocial and economic aspects (3-10). Survivors of breast cancer suffer from a perpetual risk of BCRL occurrence, with an average time of 14.4 months after treatment $(11,12)$ and an estimated risk of $14-40 \%$ after treatment completion (13). Sentinel node sampling techniques lower the risk estimation to 6-10\% (14).

Clinical manifestations of BCRL vary widely and include swelling, pain, discomfort, reduced joint dexterity due to fibrosis and hardening of affected tissues, as well as enhanced infection risk caused by static protein-rich ambience fostering bacteria. According to the National Comprehensive Cancer Network Guidelines for Survivorship, Lymphedema 2018.1 (15), lymphedema can be categorized into 4 stages as presented in Table I. In the earliest stage of BCRL, slight changes occur in the surface architecture of arms or hands of patients accompanied by feelings of limb heaviness, discomfort or both (Fig. 1A and B). The first common site of swelling is the forearm, which is usually soft and the swelling disappears by external compression. Initial swelling may also occur in the axilla, scapular region or breast. In the moderate-to-advanced stage, limb edema is no longer relieved by lifting it or by external pressure; the affected area may become larger and show a peau d'orange appearance (Fig. 2A and B). Clinical symptoms vary according to the severity and course of BCRL. 
BCRL is a natural process that ranges from initial swelling to progressive structural malformation, often occurring over a period of several weeks or months (16).

The purpose of the present review is to discuss the pathogenesis, risk factors, prevention, diagnosis and surveillance, as well as the traditional and new therapeutic approaches for BCRL.

\section{Pathogenesis}

The pathogenesis for lymphedema remains unclear, however, the traditional view of lymphatic obstruction is insufficient to explain the generation of lymphedema. There are three linked newly-presented hypotheses about the pathogenesis of BCRL.

The hypothesis of lymphatic failure. In a normal physiological state, there is a dynamic equilibrium between lymphatic load and transport capacity that makes the lymphatic system effective at absorbing and transporting lymphatic fluid back to the venous system (17). Lymphatic load refers to the volume of lymphatic fluid, which predominately includes interstitial water and protein filtrate. Transport capacity is the maximum lymphatic volume that can be transported by the lymphatics in a given period of time. However, when the transport capacity is inadequate to meet the needs of lymphatic load, lymphatic failure occurs and gives rise to interstitial edema (Fig. 3) (17).

The hemodynamic hypothesis. Total arm blood flow (volume $\mathrm{x}$ blood flow $/ \mathrm{ml}$ ) is increased in the swollen arm, but blood flow per unit volume is not elevated, causing the vasodilatation of existing resistance vessels and capillary angiogenesis near existing vessels. Capillary angiogenesis can augment the surface area of the vascular bed size, which, along with total arm blood flow, positively facilitates capillary filtration in the whole limb. When the filtration load exceeds the outflow of liquid from the tissue, edema of the limb is further aggravated, forming a vicious circle (Fig. 3) (18).

The interstitial hypothesis. Since Lymphatic failure leads to a decrease of the interstitial fluid velocity, and subsequent lymphatic regeneration and increased lymphatic vascular endothelial growth factor C (VEGF-C) (19). Lymphatic growth requires the binding of VEGF-C to the VEGF receptor (VEGFR) (20). When blood flow is absent, the increased VEGF-C diffuses to the VEGFR on blood vessels, inducing vascular endothelial growth and increasing the vascular bed size to promote capillary filtration (20). This contributes to an increased interstitial fluid volume and interstitial pressure, and the imbalance of hydrostatic pressure difference between the lymphatics and the interstitium (21). These factors in turn elicit the fluid flow towards those lymphatics, thus curtailing the production of VEGF-C and finally reaching a stable state (Fig. 3) (21). Due to the deterioration of lymphatic failure, the fluid flow rate decreases again, which induces production of VEGF-C and the cycle repeats until a new stable equilibrium is reached.

\section{Risk factors}

Currently, there is no reliable way of distinguishing patients who are likely to develop lymphedema, but a consensus has been reached on some well-defined risk factors, including axillary lymph node dissection (ALND), which is associated with early-onset disease (22), regional lymph node radiotherapy, which is related to late-onset disease (22), high body mass index (BMI) at the time of breast cancer diagnosis $\left(B M I \geq 25 \mathrm{~kg} / \mathrm{m}^{2}\right)$ (23), a high number of positive lymph nodes (>8) (24) and capsular invasion of the tumor (24).

In order to reduce the incidence rate and avoid the occurrence of BCRL, a position statement by the National Lymphedema Network has outlined the recommended preventive measures, including the avoidance of flight, trauma, skin infection, extreme temperature, venipuncture (such as blood draws) and limb compression such as blood pressure readings on the affected arm (25). However, two clinical studies demonstrated that injection, flight, blood draws and blood pressure readings were not significantly associated with the increase in arm volume, indicating that they are not risk factors for BCRL $(23,26)$. By contrast, Clark et al (27) demonstrated that hospital skin puncture was a high-risk factor for the development of BCRL.

Similarly, it remains controversial whether age and chemotherapy are risk factors for BCRL. Previous reports have suggested that younger survivors are more likely to experience lymphedema $(28,29)$ because they tend to have more aggressive tumors and more intensive therapy, but some studies have indicated that older age is a high-risk factor $(30,31)$. Other studies have shown that age is not associated with BCRL $(32,33)$. It was demonstrated that women treated with chemotherapy, specifically with taxane-based chemotherapy were more likely to develop lymphedema $(34,35)$, but with inconsistent results (36). Extreme temperature and hypertension are risk factors for BCRL that have been confirmed in certain studies $(37,38)$, however, further investigation is required. A study attempted to explore whether race affected the occurrence of BCRL, and it found that black women may have a higher prevalence of BCRL than white women (28 vs. $21 \%$ ), although the results were not statistically significant (39).

There may be a genetic predisposition for BRCL. Studies have identified several single nucleotide polymorphisms associated with the development of secondary lymphedema within the genes for hepatocyte growth factor, Met protooncogene, gap junction protein $\gamma 2$, interleukin (IL)-1A, IL-4, IL-6, IL-10, IL-13, VEGF-C, NF- $\kappa$ B, lymphocyte cytosolic protein 2, neutropilin 2, spleen-associated tyrosine kinase, vascular cell adhesion molecule 1, forkhead box C2, VEGFR2, VEGFR3 and RAR-related orphan C $(40,41)$. By identifying patients with breast cancer who harbor these molecular biomarkers, numerous precautionary measures can be taken before surgery to reduce the incidence of BCRL.

\section{Prevention}

In the initial stage of breast cancer management, especially before surgery, the assessment of risk factors and a selection of appropriate surgical scenarios are available to prevent the occurrence of BCRL (42). The BCRL rate is significantly reduced in patients who receive lumpectomy compared with those who receive total mastectomy or modified radical mastectomy (43). Historically, complete ALND is the standard treatment of axillary intervention for certain patients, 
Table I. Stages of lymphedema.

Stage Affected area Limb

0 , latent/subclinical

1 , spontaneously reversible

2 , irreversible

3 , lymphostatic elephantiasis
Lymphatic dysfunction without swelling

The accumulation of fluid and protein causing swelling; pitting edema may be overt; increased girth, heaviness, and/or stiffness Spongy tissue consistency; less evidence of pitting edema as swelling aggravation; tissue fibrosis and increased fat deposition leads to increased girth and stiffness

Severely dry, scaly, thickened skin; increased swelling and girth
A feeling of heaviness or fatigue may exist

Swelling that subsides with elevation

Swelling that does not subside with elevation

Non-pitting edema; fluid leakage and blisters are common

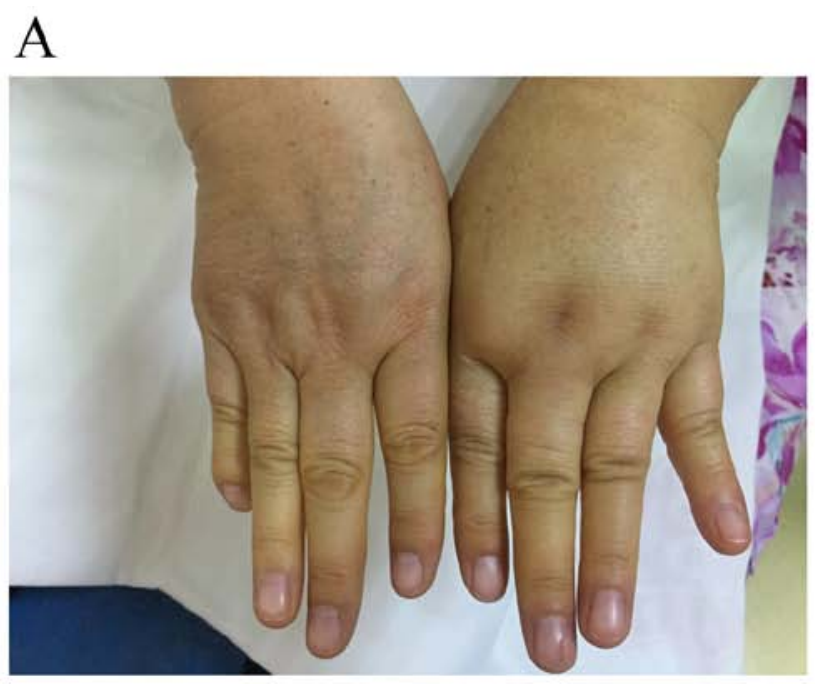

\section{B}

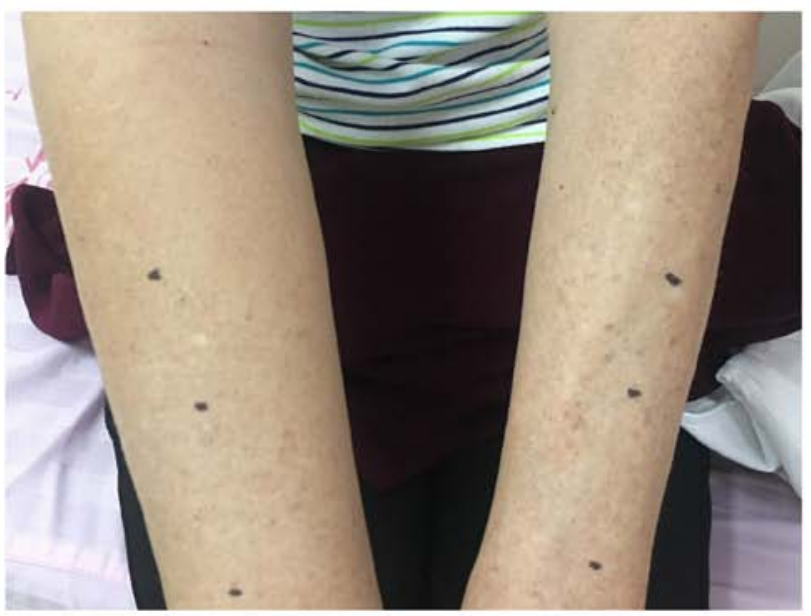

Figure 1. Early stage of breast cancer-related lymphedema. (A) Swollen hand; (B) swollen arm.

including pregnant women, male patients, patients with inflammatory breast tumor or those requiring mastectomy or receiving systemic neo-adjuvant chemotherapy. In recent years, advances have been made in identifying the population of patients who really need ALND. Findings demonstrate that axillary lymph node biopsy (ALNB) is a reliable and safe approach for predicting the status of residual nodes following systematic neo-adjuvant chemotherapy (44-46). Axillary intervention for patients undergoing mastectomy can be downgraded to sentinel lymph node dissection (47), and those who are eligible for lumpectomy can choose a feasible modality of ALNB (48), that does not increase the incidence of lymphedema (49). Axillary radiotherapy may effectively replace complete ALND to control disease relapse and metastasis in patients who have had mastectomy or y lumpectomy (50), and potentially in elderly ( $>70$ years) patients with node-negative luminal breast cancer who have undergone lumpectomy and tamoxifen treatment (51). The long-term recurrence of early-stage breast cancer is associated with biological characteristics instead of anatomical factors; therefore, avoidance of axillary intervention purely for the optimization of prognosis is suggested $(52,53)$.
In 2007, two clinical studies introduced a pioneering technique for mapping lymphatic drainage in the axillary region called axillary reverse mapping (ARM) $(54,55)$. ARM can be used to identify the lymphatic drainage of the upper extremities and the breast by injecting blue dye into the arm during the ALND procedure, resulting in the exclusive removal of lymphatics of the breast and the preservation of lymphatics of the arm to avoid the incidence of lymphedema caused by resection of arm lymphatics. This technique is underpinned by the assumption that the lymphatic drainage of the arm and breast are separate in the axillary region but are anatomically interconnected (56). An increasing body of clinical trials has confirmed a significantly lower incidence rate of BCRL in women undergoing ARM during ALND procedure compared with those receiving ALND alone (57-59). However, it is necessary to consider oncological safety when the arm nodes are conserved, particularly for patients with sentinel lymph node-positivity, as the co-localization of arm nodes and sentinel lymph nodes is as great as $27 \%$, which is a key factor in metastasis (60). Fortunately, the risk of metastasis can be lowered if patients with sentinel lymph node receive neo-adjuvant chemotherapy (61). 
A

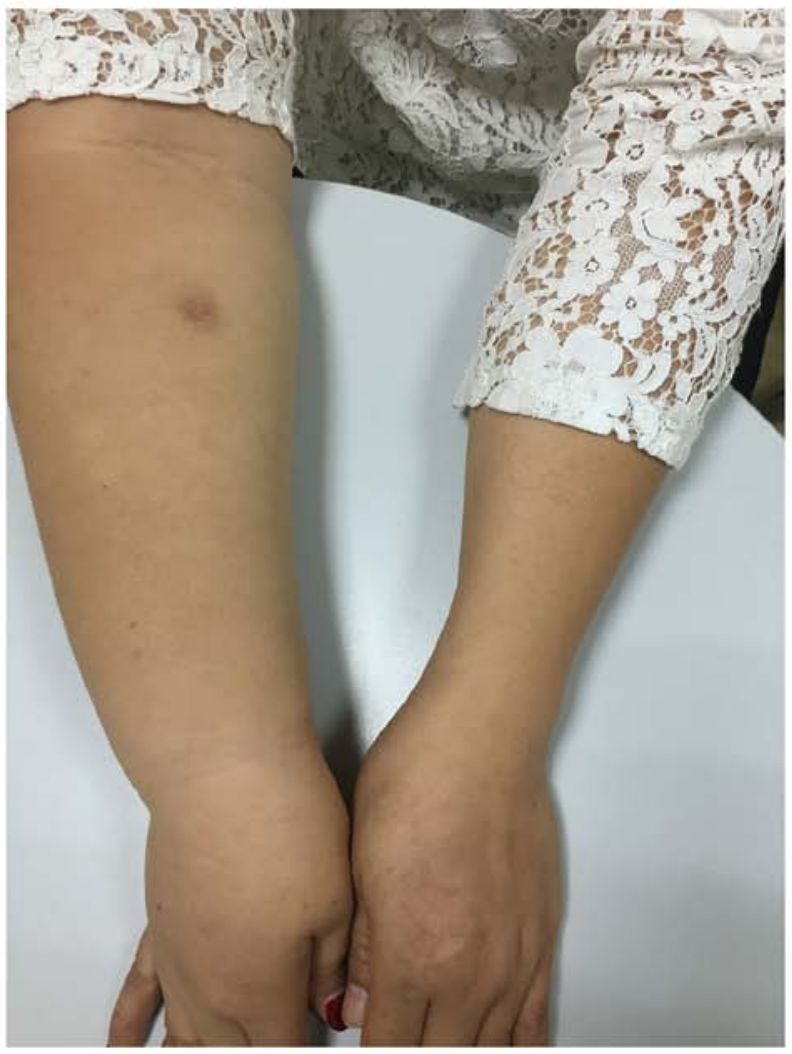

B

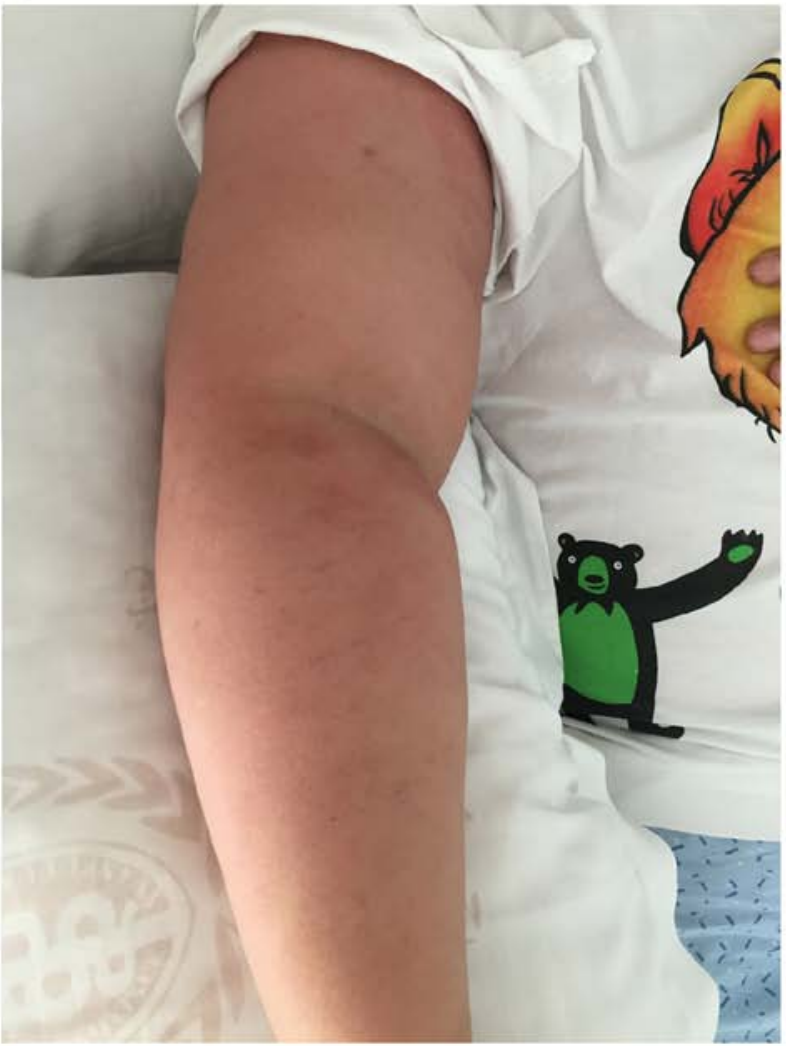

Figure 2. Advanced stage of breast cancer-related lymphedema and peau d'orange appearance of the affected limb. (A) Advanced stage of disease; (B) peau d'orange appearance of the affected limb.

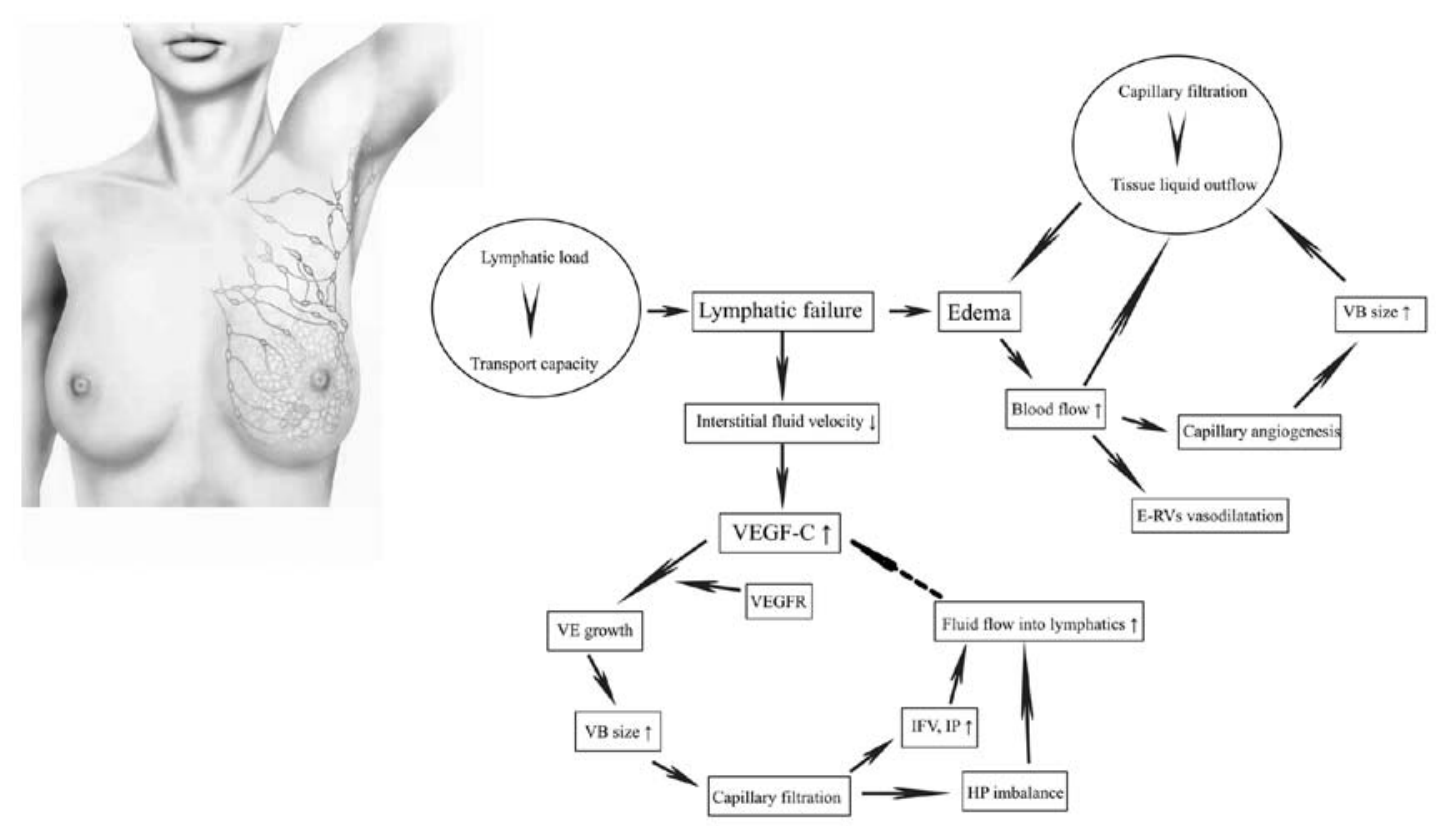

Figure 3. Pathogenesis for lymphedema. Schematic representing the pathogenesis of lymphedema. VEGF-C, vascular endothelial growth factor C; VEGFR, vascular endothelial growth factor receptor; VE, vascular endothelial; VB, vascular bed; IFV, interstitial fluid volume; IP, interstitial pressure; HP imbalance, the imbalance of hydrostatic pressure difference; E-RVs, existing resistance vessels.

\section{Diagnosis and surveillance}

Accurate diagnosis of BCRL depends on a combination of assessments that include risk evaluation, physical condition and objective examination of patients (1). The common subjective clinical symptoms are pain, swelling, numbness, arm heaviness, stiffness of affected segments and impaired joint activity, but not all patients experience these symptoms (1). Those 
considered to be at high-risk should monitor their physical condition by objective examination. An increasing number of techniques and instruments are used for objective examination of lymphedema, including limb measurements, bioimpedance spectroscopy (BIS), dual-energy X-ray absorptiometry (DXA), magnetic resonance imaging (MRI), computed tomography (CT), color Doppler imaging, lymphoscintigraphy and indocyanine green (ICG) lymphography.

Clinically, BCRL is diagnosed in terms of the degree of distortion of limb measurements. The standard methods for obtaining limb measurements include perometry, limb circumference and water displacement (1). However, results vary widely because they depend on the subjective estimation of operators, and the assessment of volume alone is insufficient (62). Diagnosis tools such as ultrasound and DXA, which allow assessment of arm tissue composition, should be recommended for patients in which the thickness of muscle in the affected arm is less than that in the unaffected arm, and the muscle growth rates differ between the arms (63). In 2018, Engin et al (64) used a new volumeter called 'easy volumeter' to measure water displacement with regard to the limb volume in patients with BCRL. The easy volumeter was designed for home use and is more durable, lightweight and easier to clean than a standard volumeter (64). In this study, the measurements from easy volumeters were valid and consistent with those of standard volumeters, suggesting that it was a promising tool to investigate BCRL (64).

In 2000, a modality was added to the diagnosis tools for lymphedema called BIS which measures the volume of extracellular fluid via detecting a physical reaction to an impressed electrical current (65). In comparison to conventional methods, the measurement of BIS is more objective and specific (80-99\%) (66-69), with a wide range of sensitivity (30-100\%) (66-70), but a higher false-negative rate (36\%) (71). Notably, BIS permits identification of lymphedema earlier, when it is in the subclinical stage, and tracks disease progression persistently, making timely intervention of lymphedema a reality (72). Timely intervention dramatically reduces the incidence rate of lymphedema from 36.4 to $4.4 \%$ (72).

DXA is effective and credible in quantifying the soft-tissue masses of the upper and lower extremities and the composition of arms, including fat, lean and bone mineral masses (73). Compared with BIS and limb circumference measurements, DXA has similar precision in detecting the percentage differences between the affected and unaffected arms (73). Moreover, DXA has superior repeatability in volume measurement yields compared with the measurements of limb circumference and water displacement, particularly in the affected arm, but not in the unaffected arm (74).

MRI has been used for decades to diagnose lymphedema, especially when it is coupled with edema in fat tissue (1). Compared to lymphoscintigraphy, MRI has a higher specificity in detecting delayed lymphatic drainage ( 85.7 vs. $66.7 \%$ ) and greater sensitivity for delineating the architecture of lymphatic vessels (100 vs. 83.3\%) (75). In some instances, the excessive water retention in subcutaneous tissue and reasons for lymphatic vessel interruption or obstruction maybe determined by this technique (1). Nevertheless, MRI is expensive and cannot achieve real-time diagnosis (76). Commonly, the detection of lymphedema is not recommended by CT or ultrasonography (US) due to their low sensitivity, but CT can be used to assess the excessive growth of fibrous tissue during the procedure of lymphedema (77). The low sensitivity of ultrasound can be attributed to several factors, including excessive edema, tissue fibrosis caused by irradiation injury and focal short-section vein occlusion beneath the clavicle or in the deep pelvis (1). Venous obstruction occurs concurrently with chronic lymphedema, with an incidence rate of $4.6 \%$, and may be falsely evaluated by US as a negative result owing to technical difficulties (78). Fortunately, this problem is solved by color Doppler imaging that can be used to visualize vessels with a diameter of only 1-2 mm, thus enabling the detection of the anatomy and function of damaged veins (78).

Provided that the aforementioned approaches cannot affirm the diagnosis, the standard recommendation is to apply radionuclide lymphoscintigraphy, a nuclear medicine imaging technique that allows visualization of lymphatic drainage into the axillary lymph nodes by subcutaneous injection of radiolabeled sulfur colloid into the hand (79). A tardive axillary visualization coupled with dermal lymphangiectasia will occur if there is lymphedema (79). Early-stage lymphoscintigraphy is an effective diagnostic tool; however, it has many disadvantages such as radiation exposure, low resolution, high costs and increased invasiveness (1). Lymphography is a newer, systematic method to evaluate limb edema and lymph circulation without radiation exposure (71). Lymphography has higher specificity and sensitivity, and longer tracking capabilities, ranging from subclinical to more advanced stages, compared with lymphoscintigraphy (77,80-82). Of note, the greatest advantage of lymphography is that it can be used for the real-time monitoring of lymphatic vessels during surgery, albeit not in a perfect way (82). For example, if the lymph vessels beneath the subcutaneous level of the skin are thicker than $2 \mathrm{~cm}$, observation cannot be achieved by ICG lymphography (82). The advantages and disadvantages of all the diagnosis tools for lymphedema are summarized in Table II.

Lymphedema surveillance can be used to identify and diagnose subclinical or early-stage disease, providing the opportunity for early intervention and treatment of BCRL (83). Prospective interval surveillance greatly optimizes the costs (84), reduces the observed incidence (72) and can reverse and prevent the progression of BCRL (85-87). Data using direct provider costs of surveillance demonstrate that it has potential to reduce direct treatment costs of BCRL management (84); however, for improving assessment, further data on the indirect costs must be reported. At present, there are four main techniques for the surveillance of BCRL: Water displacement, perometry, tonometry and BIS. Water displacement is laborious, time-consuming and not suitable for massive, continuous surveillance. Perometry, optical assessment of limb volume, is less time-consuming but more expensive. Tonometry is a noninvasive method that can detect subclinical interstitial edema via continuously measuring the dielectric constant in affected tissue and evaluating moisture content (88). BIS is more specific, but lacks sensitivity, and it may be the most frequently utilized modality (71). However, no widely adopted consensus has been reached regarding which technique is the best for the surveillance of BCRL. 
Table II. Advantages and disadvantages of diagnosis tools for LE.

$\begin{array}{lll}\text { Diagnosis tools Advantages Disadvantages } & \text { Ads }\end{array}$

Perometry; LC; WD

Radionuclide lymphoscintigraphy

Indocyanine green lymphography

Magnetic resonance imaging

Computed tomograph

toring

Color Doppler imaging

toring

Bioimpedence spectroscopy

Dual energy X-ray absorption
Diagnose LE in its early stage

Real-time monitoring without radiation exposure, high specificity and sensitivity, tracking ranging from subclinical to more advanced stage

Standard method for diagnosing LE

Diagnoses LE coupled with edema in adipose tissue, high specificity and sensitivity

Assess LE coupled with the excessive

growth of fibrous tissue

Assess LE coupled with venous obstruction

Real-time monitoring, high objectivity and specificity, tracking ranging from subclinical to more advanced stage

Quantify the soft-tissue masses and composition of arms; more repeatable to measure

volume of LE arm than LC and WD
Results vary widely and are not highly reliable, with no evaluation of arm tissue composition

Radiation exposure, low resolution, high cost, increased invasiveness, no real-time monitoring

Cannot observe deep lymphatics when the thickness of subcutaneous tissue covering them is $\geq 2 \mathrm{~cm}$

High cost without real-time monitoring

Low sensitivity, no real-time moni-

Low sensitivity, no real-time moni-

Wide range of sensitivity, high falsenegative rate

Unknown

LC, limb circumference; WD, water displacement; LE, lymphedema.

\section{Treatment}

It is widely believed that the optimal management to efficiently relieve lymphedema is complex decongestive treatment (CDT), lymphatic physiotherapeutic intervention including manual lymph drainage (MLD), skin care, physical exercise, long-term education on self-management of lymphedema, compression bandages and sleeve or stocking compression (1). Lymphoscintigraphy of upper limbs is a valid tool to predict the prognosis of this combined strategy. CDT can be provided with a commercialized product called Linfadren ${ }^{\circledR}$, which is a mixture of diosmin, coumarin and arbutin, to further improve its efficacy without any adverse events (89). Obesity reduces the effectiveness of CDT (90). Every treatment method for lymphedema has been gradually defined into explicitness.

MLD, a universal treatment for lymphedema is a massage technique that uses a special rhythmic pumping through gentle, directed stretching of skin to massage the affected area and stimulate lymphatic contractility, thus enhancing lymphatic drainage (1). A meta-analysis found that, compared with other treatments such as physical exercise, skin care and compression therapy, additional MLD was unlikely to achieve a significant reduction in the volume of the affected limb (91). Of note, heterogeneity across the analyzed studies was considerable and the sample size was limited. Paradoxically, a subgroup analysis in a Cochrane systematic review demonstrated that MLD was safe and, when used in combination with compression bandages, may provide additional benefits of swelling reduction for BCRL compared with the use of compression bandages alone, particularly for patients with mild-to-moderate disease (92). Compression bandages used with a compression garment can significantly reduce the volume of the edematous limb compared with the usage of a compression garment alone (1). Generally, the bandaging method involves a spiral-bandaging method and a figure-of-eight method (93). The figure-of-eight method is a more effective approach in maintaining the correct position, is more comfortable for the patient and has a replacement frequency of either 5 times per week over a 4 -week period or once per 2 days over a 3-week period (93). Precast adjustable compression systems, a novel technique that can be easily used and removed by patients, may be an effective alternative to compression bandages due to similar effects on reducing excess limb volume (94). When the affected limb reaches a minimum volume, self-care can be accepted by the patient (1). A myriad of advantages is attained by a CDT approach that reduces edema volume, intensity of pain and arm heaviness, reinforces lymphatic function, improves quality of life and lowers the incidence of cellulitis (95-97).

The use of adjuvant tools such as a pneumatic compression device (PCD) provides additional benefits in managing lymphedema that is associated with reduction of outpatient 
Table III. Characteristics of current treatment strategies for LE.

Treatment method

Complex decongestive

therapy

Pneumatic compression

device

Physical exercise

Lymphatic-venous 'end-to-end' anastomoses

Vascularized lymph node transfer

Liposuction
Characteristics

Reinforces lymphatic function; improves quality of life; reduces edema volume, intensity of pain and arm heaviness and the incidence of cellulitis

Reduces frequency of outpatient services and hospitalizations; reduces the usage of LE-related manual therapy, LE-related costs and incidence of cellulitis

Does not cause or worsen LE in patients; ameliorates patients psychosocial and physical conditions; results in patients having active lifestyles with optimized survival

Can only be used in the early-stage of LE; reduces limb volume or circumference; improves quality of life; minimizes trauma; lowers the risk of complications; can be performed under local anesthesia

Can only be used in the moderate-to-advanced stage of LE; reduces limb volume or circumference and the incidence of cellulitis; improves quality of life; donor-site lymph edema is a potential complication

Removes excess adipose tissue; improves lymph flow; increases blood flow to the skin; reduces the incidence of erysipelas and cellulitis

LE, lymphedema.

services and hospitalizations (1). The initial volume reduction of a swollen limb can be maintained over a long period of time by the use of PCD followed by the use of a flexible and suitable compression garment. A meta-analysis of 7 randomized controlled trials (RCTs) showed that PCD can alleviate lymphedema, however, there was no significant reduction in limb volume between conventional management of lymphedema with or without the usage of PCD (98). These RCTs had limitations such as small sample sizes of 12-56 participants with considerable heterogeneity among them (98). Currently, the most advanced PCD uses a calibrated, gradient compressor, and it is designed for home use with multiple inflatable compartments to deliver external pneumatic compression, more garment chambers and a higher level of adjustability and programmability (99). A retrospective analysis demonstrated that this adjunctive modality yields significant clinical and economic effectiveness in treating cancer-related and non-cancer-related lymphedema, demonstrated by a reduction in the adjusted rate of cellulitis, the usage of lymphedema-related manual therapy, outpatient visits and total lymphedema-related costs per patient, excluding medical equipment costs (99).

It is widely known that a sedentary lifestyle leads to being overweight or obese, factors that are associated with an increased incidence of BCRL (14). Participation in physical exercise during and after treatment for breast cancer can ameliorate psychosocial and physical conditions, resulting in active lifestyles with optimized survival (100). Traditionally, patients with lymphedema or who are at risk for lymphedema tend to reduce physical exercise due to concerns about disease exacerbation (100). Some preliminary studies have indicated that exercise neither causes lymphedema nor worsens the disease (101-105). A slowly progressive weight-lifting program does not increase the rate of lymphedema compared with no exercise, and aerobic exercise, resistance training, stretching, yoga, qigong and pilates are also safe $(101,105)$. Under specific circumstances, resistance training can even substantially improve the lymphedema state and may prevent the development of secondary lymphedema in patients (106).

There are a variety of surgical techniques for lymphedema, including debulking resection, liposuction, lymphatic-venous 'end-to-end' anastomoses (LVA) and vascularized lymph node (VLN) transplantation with the advent of microsurgery (1). Typically, LVA is only used in the early-stage of the disease, but despite this limitation it reduces limb volume or circumference effectively and improves quality of life (107-109). LVA also has other advantages such as reducing trauma, lowering the risk of complications and it can be performed under local anesthesia $(110,111)$. After a 1-year follow-up of women undergoing LVA, $>56.5 \%$ of anastomoses are still patent (109).

A new program, called the 'Lymphedema Microsurgical Preventive Healing Approach (LYMPHA)', combines the LVA technique with the surgery of ALND, which anastomoses the collateral branch of the axillary vein to the lymphatics of the arm, with a low incidence rate of lymphedema of $4.05 \%(112,113)$. An altered and simplified version of LYMPHA used during the surgery of ALND dramatically decreases the lymphedema rate to $3 \%$ compared with ALND alone, which has a higher rate of $13 \%$ (114). Two pilot studies proposed a new technique called 'dynamic-lymphaticovenular anastomosis,' which uses preoperative dynamic imaging of the forearm to determine the incision points followed by microsurgery of LVA $(115,116)$. This technique achieves significant reduction of excess limb volume compared with conventional LVA and results in no swelling rebound after postoperative degradation or removal of compression garments in a 12 month follow up period $(115,116)$.

VLN transfer is a promising technique for treating moderate-to-advanced stage lymphedema, and it has the ability to lower the clinical grade, attenuate limb circumference, reduce the incidence of cellulitis and improve the quality of life in patients (117). However, it requires a strict observation 
of the donor site because donor site lymphedema is the most serious complication after this surgery (117). Patient selection and scrupulous assessment of donor and recipient sites prior to VLN transplantation are key factors for surgical success. This concern may be removed by the technique of vascularized groin lymph node (VGLN) flap transplantation (118). Findings revealed VGLN flap harvesting does not cause iatrogenic lymphedema at the donor site, but this surgery cannot be performed in patients with a high risk of lower limb lymphedema due to obesity, pre-existing lower limb edema or previous pelvic surgery (118). Of note, the limitations of LVA and VLN procedures have to be emphasized, as they are complex and can only be provided by experts at tertiary care centers.

CDT is not an effective treatment for chronic massive lymphedema with excess adipose tissue, as adipose tissue cannot be eliminated through compression alone (1). Microsurgery often fails to attain complete limb reduction because the newly formed adipose tissue persisting under the skin of the patient with longstanding non-pitting lymphedema is not resected. These perplexities are solved by the use of liposuction, which can remove excess adipose tissue, resulting in complete reduction of lymphedema (1). Liposuction is effective in removing chronic non-pitting limb lymphedema with a large volume, which can be completely attenuated in 1-3 months, with no recurrence of arm swelling observed in long-term follow-up (119-123). Ample evidence suggests that women with lymphedema who undergo liposuction followed by compression bandages or compression garments achieve significant benefits, as the mean reduction of excess limb volume ranges from 101-118\% (124-126) and can be maintained at $>100 \%$ during 21 years of follow-up (127). In addition, liposuction improves lymph flow (128), increases blood flow to the skin so that it is approximately equal to the flow in a normal arm (129), and it does not injure the existing lymphatic vessels within the affected limb $(122,130)$. These characteristics significantly reduce the incidence of erysipelas and cellulitis (131). The complications from liposuction are limited, with a very low incidence rate; paresthesia of the skin is the most typical complication and fades away within 3-6 months (132), and fibrous tissue increases in some cases, specifically in women with a male distribution of body fat (132). The characteristics of current treatment scenarios for lymphedema are summarized in Table III.

Previous findings illustrated that no medication has the capacity to reduce lymphedema, as the lymphatic flow could not be improved by any drugs, including diuretics that change microvascular fluid filtration by increasing the excretion of sodium chloride and water (96). With a greater understanding of the molecular mechanisms that control lymphatic function, lymphedema may be reversed. The first potential medication for the treatment of BCRL is reported to be in phase I trials (133). An increasing number of lymphedema therapy-related preclinical investigations are performed in animal models of lymphatic disease in which the genes encoding VEGF-C or VEFG-D are transferred into the animal by adenoviruses or adeno-associated viruses $(134,135)$. This technique results in the development of many new lymphatic capillaries and reduces edema following an initial promotion of lymphatic extravasation (136). Following VEGF-C therapy, the injured collecting lymphatic vessels in mice undergo regeneration of lymphatic capillaries, which subsequently remodel, differentiate and mature into functional vessels (137). Similarly, surgery-based damage of lymphatic vasculature in pigs can be effectively repaired by VEGF-C therapy, which greatly enhances the function and structural stability of transferred lymph nodes (138). The combined program of the microsurgery of VLN transfer followed by VEGF-C treatment may be also equally beneficial in patients with lymphedema to foster lymphatic microvascular anastomoses.

The success of stem cell therapy involving the transplantation of autologous mesenchymal stromal cells derived from adipose tissue, muscle and bone marrow to alleviate lymphedema has been reported in certain preclinical studies (139-141), and this has opened up a potential new field of treatment for this disease. In two pilot studies, injection of adipose-derived regenerative cells into the axillary region with fat grafting was well-tolerated, and only a paucity of liposuction-related adverse events occurred transiently $(142,143)$. After 6-12 months of follow-up, lymphedema was alleviated, without rebound of the swelling limb (143). However, these promising results of autologous stem cell therapy from the two studies must be investigated in humans with RCTs. If the results in humans are positive, increasing number of patients with lymphedema could benefit from this surgery.

\section{Conclusions}

BCRL exerts a negative impact on the quality of life of survivors of breast cancer. Precautionary measures and earlier lymphedema surveillance combined with effective diagnostic tools, such as BIS or ICG lymphography, are effective in reducing the incidence of lymphedema and providing more opportunities for intervention and treatment in subclinical and early-stages, especially in high-risk patients. In a variety of treatment strategies, the combination of CDT, PCD and appropriate physical exercise can contribute to women having an apparent reduction of excess limb volume and improvement of quality of life. Of the surgical techniques, the usage of LVA in the early-stage of disease, VLN transplantation in the moderate-to-advanced stage and liposuction when lymphedema is coupled with excess adipose tissue can reduce swollen limb volume to normal, and be maintained long-term without rebound of swelling. Recently, molecular therapy and autologous stem cell transplantation have been shown to successfully alleviate lymphedema in preclinical studies, which may lead to the development of novel targeted therapies for BCRL in the future.

\section{Acknowledgements}

The authors would like to acknowledge Dr Han Qin (Department of Sport Medicine, The Affiliated Hospital of Qingdao University, Qingdao, China) for providing the map of lymphatics of the breast.

\section{Funding}

No funding was received. 


\section{Availability of data and materials}

Not applicable.

\section{Authors' contributions}

LH made substantial contributions to the conception of the review, HQ produced software that was used in the work, QW drafted the manuscript and substantively revised it, and YS contributed to the writing of the manuscript.

\section{Ethics approval and consent to participate}

Not applicable.

\section{Patient consent for publication}

Not applicable.

\section{Competing interests}

The authors declare that they have no competing interests.

\section{References}

1. Rockson SG: Lymphedema after Breast Cancer Treatment. N Eng J Med 379: 1937-1944, 2018

2. Armer JM, Ballman KV, McCall L, Armer NC, Sun Y, Udmuangpia T, Hunt KK, Mittendorf EA, Byrd DR, Julian TB and Boughey JC: Lymphedema symptoms and limb measurement changes in breast cancer survivors treated with neoadjuvant chemotherapy and axillary dissection: Results of American college of surgeons oncology group (ACOSOG) Z1071 (Alliance) substudy. Support Care Cancer 27: 495-503, 2019.

3. Velanovich V and Szymanski W: Quality of life of breast cancer patients with lymphedema. Am J Surg 177: 184-187, 1999.

4. Casley-Smith JR and Casley-Smith JR: Modern treatment of lymphoedema II. The benzopyrones. Australas J Dermatol 33: 69-74, 1992.

5. MM H: Functional and psychosocial aspects of lymphedema in women treated for breast cancer. Innov Breast Cancer Care 3: 97-100, 17-18.

6. Armer JM and Mallinckrodt BR: Post-breast cancer treatment lymphedema: The secret epidemic Scope Phlebolog Lympholog 9: 334-341, 2002.

7. Carter BJ: Women's experiences of lymphedema. Oncol Nurs Forum 24: 875-882, 1997.

8. Newman ML, Brennan M and Passik S: Lymphedema complicated by pain and psychological distress: A case with complex treatment needs. J Pain Symptom Manage 12: 376-379, 1996.

9. Passik SD and McDonald MV: Psychosocial aspects of upper extremity lymphedema in women treated for breast carcinoma. Cancer 83 (12 Suppl American): 2817-2820, 1998.

10. Tobin MB, Lacey HJ, Meyer L and Mortimer PS: The psychological morbidity of breast cancer-related arm swelling. Psychological morbidity of lymphoedema. Cancer 72: 3248-3252, 1993.

11. DiSipio T, Rye S, Newman B and Hayes S: Incidence of unilateral arm lymphoedema after breast cancer: A systematic review and meta-analysis. Lancet Oncol 14: 500-515, 2013.

12. Specht MC, Miller CL, Russell TA, Horick N, Skolny MN, O'Toole JA, Jammallo LS, Niemierko A, Sadek BT, Shenouda MN, et al: Defining a threshold for intervention in breast cancer-related lymphedema: What level of arm volume i ncrease predicts progression? Breast cancer research and treatment 140: 485-494, 2013.

13. Rockson SG and Rivera KK: Estimating the population burden of lymphedema. Ann N Y Acad Sci 1131: 147-154, 2008.

14. Hayes S, Cornish B and Newman B: Comparison of methods to diagnose lymphoedema among breast cancer survivors: 6-month follow-up. Breast Cancer Res Treat 89: 221-226, 2005.
15. Denlinger CS, Sanft T, Baker KS, Broderick G, Demark-Wahnefried W, Friedman DL, Goldman M, Hudson M, Khakpour N, King A, et al: Survivorship, version 2.2018, NCCN clinical practice guidelines in oncology. J Natl Compr Cancer Netw 16: 1216-1247, 2018.

16. International Society of Lymphology: The diagnosis and treatment of peripheral lymphedema. 2009 concensus document of the international society of lymphology. Lymphology 42: 51-60, 2009.

17. Lawenda BD, Mondry TE and Johnstone PA: Lymphedema: A primer on the identification and management of a chronic condition in oncologic treatment. CA Cancer J Clin 59: 8-24, 2009.

18. Mortimer PS: The pathophysiology of lymphedema. Cancer 83(12 Suppl American): 2798-2802, 1998.

19. Goldman J, Conley KA, Raehl A, Bondy DM, Pytowski B, Swartz MA, Rutkowski JM, Jaroch DB and Ongstad EL: Regulation of lymphatic capillary regeneration by interstitial flow in skin. Am J Physiol Heart Circ Physiol 292: H2176-H2183, 2007.

20. Joukov V, Pajusola K, Kaipainen A, Chilov D, Lahtinen I, Kukk E, Saksela O, Kalkkinen N and Alitalo K: A novel vascular endothelial growth factor, VEGF-C, is a ligand for the Flt4 (VEGFR-3) and KDR (VEGFR-2) receptor tyrosine kinases. EMBO J 15: 290-298, 1996.

21. Pajusola Kaipainen Chilov Lahtinen Kukk Saksela O, Kalkkinen N and Alitalo K: 2, 199621. Bates DO: An interstitial hypothesis for breast cancer related lymphoedema. Pathophysiology 17: 289-294, 2010.

22. McDuff SGR, Mina AI, Brunelle CL, Salama L, Warren LEG, Abouegylah M, Swaroop M, Skolny MN, Asdourian M, Gillespie T, et al: Timing of lymphedema after treatment for breast cancer: When are patients most at risk? Int J Radiat Oncol Biol Phys 103: 62-70, 2019.

23. Asdourian MS, Swaroop MN, Sayegh HE, Brunelle CL, Mina AI, Zheng H, Skolny MN and Taghian AG: Association between precautionary behaviors and breast cancer-related lymphedema in patients undergoing bilateral surgery. J Clin Oncol 35: 3934-3941, 2017.

24. Iyigun ZE, Duymaz T, Ilgun AS, Alco G, Ordu C, Sarsenov D, Aydin AE, Celebi FE, Izci F, Eralp Y and Ozmen V: Preoperative lymphedema-related risk factors in early-stage breast cancer. Lymphat Res Biol 16: 28-35, 2018.

25. Network NL: Lymphedema risk reduction practices. http://wwwlymphnetorg/pdfDocs/nlnriskreductionpdf 2012.

26. Ferguson CM, Swaroop MN, Horick N, Skolny MN, Miller CL, Jammallo LS, Brunelle C, O'Toole JA, Salama L, Specht MC and Taghian AG: Impact of ipsilateral blood draws, injections, blood pressure measurements, and air travel on the risk of lymphedema for patients treated for breast cancer. J Clin Oncol 34: 691-698, 2016.

27. Clark B, Sitzia J and Harlow W: Incidence and risk of arm oedema following treatment for breast cancer: A three-year follow-up study. QJM 98: 343-348, 2005.

28. Geller BM, Vacek PM, O'Brien P and Secker-Walker RH: Factors associated with arm swelling after breast cancer surgery. J Womens Health (Larchmt) 12: 921-930, 2003.

29. Armer J and Fu MR: Age differences in post-breast cancer lymphedema signs and symptoms. Cancer Nurs 28: 200-207; quiz208-209, 2005.

30. Larson D, Weinstein M, Goldberg I, Silver B, Recht A, Cady B, Silen W and Harris JR: Edema of the arm as a function of the extent of axillary surgery in patients with stage I-II carcinom a of the breast treated with primary radiotherapy. Int J Radiat Oncol Biol Phys 12: 1575-1582, 1986.

31. Engel J, Kerr J, Schlesinger-Raab A, Sauer H and Holzel D: Axilla surgery severely affects quality of life: Results of a 5-year prospective study in breast cancer patients. Breast Cancer Res Treat 79: 47-57, 2003.

32. Paskett ED, Naughton MJ, McCoy TP, Case LD and Abbott JM: The epidemiology of arm and hand swelling in premenopausal breast cancer survivors. Cancer Epidemiol Biomarkers Prev 16: 775-782, 2007.

33. Pezner RD, Patterson MP, Hill LR, Lipsett JA, Desai KR, Vora N, Wong JY and Luk KH: Arm lymphedema in patients treated conservatively for breast cancer: Relationship to patient age and axillary node dissection technique. Int $\mathrm{J}$ Radiat Oncol Biol Phys 12: 2079-2083, 1986.

34. Cariati M, Bains SK, Grootendorst MR, Suyoi A, Peters AM, Mortimer P, Ellis P, Harries M, Van Hemelrijck M and Purushotham AD: Adjuvant taxanes and the development of breast cancer-related arm lymphoedema. Br J Surg 102: 1071-1078, 2015. 
35. Penn IW, Chang YC, Chuang E, Chen CM, Chung CF, Kuo CY and Chuang TY: Risk factors and prediction model for persistent breast-cancer-related lymphedema: A 5-year cohort study. Support Care Cancer 27: 991-1000, 2019.

36. Swaroop MN, Ferguson CM, Horick NK, Skolny MN, Miller CL, Jammallo LS, Brunelle CL, O'Toole JA, Isakoff SJ, Specht MC and Taghian AG: Impact of adjuvant taxane-based chemotherapy on development of breast cancer-related lymphedema: Results from a large prospective cohort. Breast Cancer Res Treat 151: 393-403, 2015

37. Czerniec SA, Ward LC and Kilbreath SL: Breast cancer-related arm lymphedema: Fluctuation over six months and the effect of the weather. Lymphat Res Biol 14: 148-155, 2016.

38. Rockson SG: Precipitating factors in lymphedema: Myths and realities. Cancer 83(12 Suppl American): 2814-2846, 1998.

39. Meeske KA, Sullivan-Halley J, Smith AW, McTiernan A, Baumgartner KB, Harlan LC and Bernstein L: Risk factors for arm lymphedema following breast cancer diagnosis in Black women and White women. Breast Cancer Res Treat 113 : 383-391, 2009.

40. Visser J, van Geel M, Cornelissen AJM, van der Hulst RRWJ and Qiu SS: Breast cancer-related lymphedema and genetic predisposition: A systematic review of the literature. Lymphat Res Biol 17: 288-293, 2019.

41. Newman B, Lose F, Kedda MA, Francois M, Ferguson K, Janda M, Yates P, Spurdle AB and Hayes SC: Possible genetic predisposition to lymphedema after breast cancer. Lymphat Res Biol 10: 2-13, 2012 .

42. Tandra P, Kallam A and Krishnamurthy J: Identification and management of lymphedema in patients with breast cancer. J Oncol pract 15: 255-262, 2019.

43. Tsai RJ, Dennis LK, Lynch CF, Snetselaar LG, Zamba GK and Scott-Conner C: The risk of developing arm lymphedema among breast cancer survivors: A meta-analysis of treatment factors. Ann Surg Oncol 16: 1959-1972, 2009.

44. Gentilini $\mathrm{O}$ and Veronesi U: Abandoning sentinel lymph node biopsy in early breast cancer? A new trial in progress at the European institute of oncology of milan (SOUND: Sentinel node vs observation after axillary UltraSouND). Breast 21: 678-681, 2012.

45. Cardoso F, van't Veer LJ, Bogaerts J, Slaets L, Viale G, Delaloge S, Pierga JY, Brain E, Causeret S, DeLorenzi M, et al: 70-Gene signature as an aid to treatment decisions in early-stage breast cancer. N Engl J Med 375: 717-729, 2016.

46. Sparano JA, Gray RJ, Makower DF, Pritchard KI, Albain KS Hayes DF, Geyer CE Jr, Dees EC, Perez EA, Olson JA Jr, et al: Prospective validation of a 21-gene expression assay in breast cancer. N Engl J Med 373: 2005-2014, 2015.

47. Gradishar WJ, Anderson BO, Balassanian R, Blair SL, Burstein HJ, Cyr A, Elias AD, Farrar WB, Forero A, Giordano SH, et al: NCCN guidelines insights: Breast cancer, version 1.2017. J Natl Compr Canc Netw 15: 433-451, 2017.

48. Levenhagen K, Davies C, Perdomo M, Ryans K and Gilchrist L: Diagnosis of upper quadrant lymphedema secondary to cancer: Clinical practice guideline from the oncology section of the American physical therapy association. Phys Ther 97: 729-745, 2017.

49. Lyman GH, Somerfield MR, Bosserman LD, Perkins CL, Weaver DL and Giuliano AE: Sentinel lymph node biopsy for patients with early-stage breast cancer: American society of clinical oncology clinical practice guideline update. J Clin Oncol 35: 561-564, 2017

50. International Society of Lymphology: The diagnosis and treatment of peripheral lymphedema: 2013 Consensus document of the international society of lymphology. Lymphology 46: 1-11, 2013.

51. Hughes KS, Schnaper LA, Bellon JR, Cirrincione CT, Berry DA, McCormick B, Muss HB, Smith BL, Hudis CA, Winer EP and Wood WC: Lumpectomy plus tamoxifen with or without irradiation in women age 70 years or older with early breast cancer: Long-term follow-up of CALGB 9343. J Clin Oncol 31: 2382-2387, 2013.

52. Czerniec SA, Ward LC, Refshauge KM, Beith J, Lee MJ, York S and Kilbreath SL: Assessment of breast cancer-related arm lymphedema--comparison of physical measurement methods and self-report. Cancer Invest 28: 54-62, 2010.

53. Cormier JN, Xing Y, Zaniletti I, Askew RL, Stewart BR and Armer JM: Minimal limb volume change has a significant impact on breast cancer survivors. Lymphology 42: 161-175, 2009.
54. Thompson M, Korourian S, Henry-Tillman R, Adkins L, Mumford S, Westbrook KC and Klimberg VS: Axillary reverse mapping (ARM): A new concept to identify and enhance lymphatic preservation. Ann Surg Oncol 14 1890-1895, 2007.

55. Nos C, Lesieur B, Clough KB and Lecuru F: Blue dye injection in the arm in order to conserve the lymphatic drainage of the arm in breast cancer patients requiring an axillary dissection. Ann Surg Oncol 14: 2490-2496, 2007.

56. Pavlista D and Eliska O: Analysis of direct oil contrast lymphography of upper limb lymphatics traversing the axilla - a lesson from the past - contribution to the concept of axillary reverse mapping. Eur J Surg Oncol 38: 390-394, 2012

57. Gennaro M, Maccauro M, Sigari C, Casalini P, Bedodi L, Conti AR, Caraceni A and Bombardieri E: Selective axillary dissection after axillary reverse mapping to prevent breast-cancer-related lymphoedema. Eur J Surg Oncol 39: 1341-1345, 2013.

58. Pasko JL, Garreau J, Carl A, Ansteth M, Glissmeyer M and Johnson N: Axillary reverse lymphatic mapping reduces patient perceived incidence of lymphedema after axillary dissection in breast cancer. Am J Surg 209: 890-895, 2015.

59. Yue T, Zhuang D, Zhou P, Zheng L, Fan Z, Zhu J, Hou L, Yu F, Dong X, Xiao L and He Q: A prospective study to assess the feasibility of axillary reverse mapping and evaluate its effect on preventing lymphedema in breast cancer patients. Clin Breast Cancer 15: 301-306, 2015.

60. Noguchi M, Noguchi M, Ohno Y, Morioka E, Nakano Y, Kosaka T, Kurose N and Minato H: Feasibility study of axillary reverse mapping for patients with clinically node-negative breast cancer. Eur J Surg Oncol 42: 650-656, 2016.

61. Beek MA, Gobardhan PD, Klompenhouwer EG, Rutten HJ, Voogd AC and Luiten EJ: Axillary reverse mapping (ARM) in clinically node positive breast cancer patients. Eur J Surg Oncol 41: 59-63, 2015.

62. McLaughlin SA, Staley AC, Vicini F, Thiruchelvam P, Hutchison NA, Mendez J, MacNeill F, Rockson SG, DeSnyder SM, Klimberg S, et al: Considerations for clinicians in the diagnosis, prevention, and treatment of breast cancer-related lymphedema: Recommendations from a multidisciplinary expert ASBrS panel: Part 1: Definitions, assessments, education, and future directions. Ann Surg Oncol 24: 2818-2826, 2017.

63. Bok SK, Jeon Y and Hwang PS: Ultrasonographic evaluation of the effects of progressive resistive exercise in breast cancer-related lymphedema. Lymphat Res Biol 14: 18-24, 2016.

64. Engin O, Akalin E, Saribay E, Aslan C, Sahin E and Alper S: Easy volumeter in detection of breast cancer-related lymphedema: A validity study. Lymphat Res Biol 17: 543-549, 2019.

65. Cornish BH, Chapman M, Thomas BJ, Ward LC, Bunce IH and Hirst C: Early diagnosis of lymphedema in postsurgery breast cancer patients. Ann N Y Acad Sci 904: 571-575, 2000.

66. Cornish BH, Chapman M, Hirst C, Mirolo B, Bunce IH, Ward LC and Thomas BJ: Early diagnosis of lymphedema using multiple frequency bioimpedance. Lymphology 34: 2-11, 2001 .

67. Bundred NJ, Stockton C, Keeley V, Riches K, Ashcroft L, Evans A, Skene A, Purushotham A, Bramley M and Hodgkiss T; Investigators of BEA/PLACE studies: Comparison of multi-frequency bioimpedance with perometry for the early detection and intervention of lymphoedema after axillary node clearance for breast cancer. Breast Cancer Res Treat 151: $121-129,2015$

68. Fu MR, Cleland CM, Guth AA, Kayal M, Haber J, Cartwright F Kleinman R, Kang Y, Scagliola J and Axelrod D: L-dex ratio in detecting breast cancer-related lymphedema: Reliability, sensitivity, and specificity. Lymphology 46: 85-96, 2013.

69. Barrio AV, Eaton A and Frazier TG: A prospective validation study of bioimpedance with volume displacement in early-stage breast cancer patients at risk for lymphedema. Ann Surg Oncol 22 (Suppl 3): S370-S375, 2015.

70. Czerniec SA, Ward LC, Lee MJ, Refshauge KM, Beith J and Kilbreath SL: Segmental measurement of breast cancer-related arm lymphoedema using perometry and bioimpedance spectroscopy. Support Care Cancer 19: 703-710, 2011.

71. Qin ES, Bowen MJ and Chen WF: Diagnostic accuracy of bioimpedance spectroscopy in patients with lymphedema: A retrospective cohort analysis. J Plast Reconstr Aesthet Surg 71: 1041-1050, 2018. 
72. Soran A, Ozmen T, McGuire KP, Diego EJ, McAuliffe PF, Bonaventura M, Ahrendt GM, DeGore L and Johnson R: The importance of detection of subclinical lymphedema for the prevention of breast cancer-related clinical lymphedema after axillary lymph node dissection; A prospective observational study. Lymphat Res Biol 12: 289-294, 2014.

73. Newman AL, Rosenthall L, Towers A, Hodgson P, Shay CA, Tidhar D, Vigano A and Kilgour RD: Determining the precision of dual energy x-ray absorptiometry and bioelectric impedance spectroscopy in the assessment of breast cancer-related lymphedema. Lymphat Res Biol 11: 104-109, 2013.

74. Gjorup C, Zerahn B and Hendel HW: Assessment of volume measurement of breast cancer-related lymphedema by three methods: Circumference measurement, water displacement, and dual energy X-ray absorptiometry. Lymphat Res Biol 8: 111-119, 2010.

75. Bae JS, Yoo RE, Choi SH, Park SO, Chang H, Suh M and Cheon GJ: Evaluation of lymphedema in upper extremities by MR lymphangiography: Comparison with lymphoscintigraphy. Magn Reson Imaging 49: 63-70, 2018.

76. Partsch H: Practical aspects of indirect lymphography and lymphoscintigraphy. Lymphat Res Biol 1: 71-73; discussion 73-74, 2003.

77. Mihara M, Hara H, Araki J, Kikuchi K, Narushima M, Yamamoto T, Iida T, Yoshimatsu H, Murai N, Mitsui K, et al Indocyanine green (ICG) lymphography is superior to lymphoscintigraphy for diagnostic imaging of early lymphedema of the upper limbs. PloS One 7: e38182, 2012.

78. Szuba A, Razavi M and Rockson SG: Diagnosis and treatment of concomitant venous obstruction in patients with secondary lymphedema. J Vasc Interv Radiol 13: 799-803, 2002.

79. Rockson SG: Lymphedema after breast cancer treatment. N Engl J Med 380: 694, 2019.

80. Chen WF, Zhao H, Yamamoto T, Hara $\mathrm{H}$ and Ding J: Indocyanine green lymphographic evidence of surgical efficacy following microsurgical and supermicrosurgical lymphedema reconstructions. J Reconstr Microsurg 32: 688-698, 2016.

81. Yamamoto T, Matsuda N, Doi K, Oshima A, Yoshimatsu H, Todokoro T, Ogata F, Mihara M, Narushima M, Iida T and Koshima I: The earliest finding of indocyanine green lymphography in asymptomatic limbs of lower extremity lymphedema patients secondary to cancer treatment: The modified dermal backflow stage and concept of subclinical lymphedema. Plast Reconstr Surg 128: 314e-321e, 2011.

82. Yamamoto T, Yoshimatsu H, Narushima M, Yamamoto N, Hayashi A and Koshima I: Indocyanine green lymphography findings in primary leg lymphedema. Eur J Vasc Endovasc Surg 49: 95-102, 2015.

83. Torres Lacomba M, Yuste Sánchez MJ, Zapico Goñi A Prieto Merino D, Mayoral del Moral O, Cerezo Téllez E and Minayo Mogollón E: Effectiveness of early physiotherapy to prevent lymphoedema after surgery for breast cancer: Randomised, single blinded, clinical trial. BMJ 340: b5396, 2010.

84. Stout NL, Pfalzer LA, Springer B, Levy E, McGarvey CL, Danoff JV, Gerber LH and Soballe PW: Breast cancer-related lymphedema: Comparing direct costs of a prospective surveillance model and a traditional model of care. Phys Ther 92 152-163, 2012.

85. Stout Gergich NL, Pfalzer LA, McGarvey C, Springer B, Gerber LH and Soballe P: Preoperative assessment enables the early diagnosis and successful treatment of lymphedema. Cancer 112: 2809-2819, 2008.

86. Boccardo FM, Ansaldi F, Bellini C, Accogli S, Taddei G, Murdaca G, Campisi CC, Villa G, Icardi G, Durando P, et al Prospective evaluation of a prevention protocol for lymphedema following surgery for breast cancer. Lymphology 42: 1-9, 2009.

87. Box RC, Reul-Hirche HM, Bullock-Saxton JE and Furnival CM: Physiotherapy after breast cancer surgery: Results of a randomised controlled study to minimise lymphoedema. Breast Cancer Res Treat 75: 51-64, 2002.

88. Czerniec SA, Ward LC and Kilbreath SL: Assessment of breast cancer-related lymphedema: A comparison of moisture meter and spot bioimpedance measurement. Lymphat Res Biol 13 $10-19,2015$

89. Cacchio A, Prencipe R, Bertone M, De Benedictis L, Taglieri L, D'Elia E, Centoletti C and Di Carlo G: Effectiveness and safety of a product containing diosmin, coumarin, and arbutin (Linfadren $\AA$ ) in addit ion to complex decongestive therapy on management of breast cancer-related lymphedema. Support Care Cancer 27: 1471-1480, 2019.
90. Duyur Cakit B, Pervane Vural S and Ayhan FF: Complex decongestive therapy in breast cancer-related lymphedema: Does obesity affect the outcome negatively? Lymphat Res Biol 17: 45-50, 2019.

91. Huang TW, Tseng SH, Lin CC, Bai CH, Chen CS, Hung CS, $\mathrm{Wu} \mathrm{CH}$ and Tam KW: Effects of manual lymphatic drainage on breast cancer-related lymphedema: A systematic review and meta-analysis of randomized controlled trials. World J Surg Oncol 11: 15, 2013

92. Ezzo J, Manheimer E, McNeely ML, Howell DM, Weiss R, Johansson KI, Bao T, Bily L, Tuppo CM, Williams AF and Karadibak D: Manual lymphatic drainage for lymphedema following breast cancer treatment. Cochrane Database Syst Rev 21: CD003475, 2015.

93. Johansson K, Albertsson M, Ingvar C and Ekdahl C: Effects of compression bandaging with or without manual lymph drainage treatment in patients with postoperative arm lymphedema. Lymphology 32: 103-110, 1999.

94. Pujol-Blaya V, Salinas-Huertas S, Catasus ML, Pascual T and Belmonte R: Effectiveness of a precast adjustable compression system compared to multilayered compression bandages in the treatment of breast cancer-related lymphoedema: A randomized, single-blind clinical trial. Clin Rehabil 33: 631-641, 2019.

95. Mobarakeh ZS, Mokhtari-Hesari P, Lotfi-Tokaldany M, Montazeri A, Heidari M and Zekri F: Combined decongestive therapy and reduction of pain and heaviness in patients with breast cancer-related lymphedema. Support Care Cancer 27: 3805-3811, 2019.

96. Moffatt CJ, Doherty DC, Franks PJ and Mortimer PS: Community-based treatment for chronic edema: An effective service model. Lymphat Res Biol 16: 92-99, 2018.

97. Ochalek K, Partsch H, Gradalski T and Szygula Z: Do compression sleeves reduce the incidence of arm lymphedema and improve quality of life? two-year results from a prospective randomized trial in breast cancer survivors. Lymphat Res Biol 17: 70-77, 2019.

98. Shao Y, Qi K, Zhou QH and Zhong DS: Intermittent pneumatic compression pump for breast cancer-related lymphedema: A systematic review and meta-analysis of randomized controlled trials. Oncol Res Treat 37: 170-174, 2014.

99. Karaca-Mandic P, Hirsch AT, Rockson SG and Ridner SH: The cutaneous, net clinical, and health economic benefits of advanced pneumatic compression devices in patients with lymphedema. JAMA Dermatol 151: 1187-1193, 2015.

100. Hayes SC, Reul-Hirche H and Turner J: Exercise and secondary lymphedema: Safety, potential benefits, and research issues. Med Sci Sports Exerc 41: 483-489, 2009.

101. Ahmed RL, Thomas W, Yee D and Schmitz KH: Randomized controlled trial of weight training and lymphedema in breast cancer survivors. J Clin Oncol 24: 2765-2772, 2006.

102. Harris SR and Niesen-Vertommen SL: Challenging the myth of exercise-induced lymphedema following breast cancer: A series of case reports. J Surg Oncol 74: 95-98: Discussion 98-99, 2000.

103. Lane K, Jespersen D and McKenzie DC: The effect of a whole body exercise programme and dragon boat training on arm volume and arm circumference in women treated for breast cancer. Eur J Cancer Care (Engl) 14: 353-358, 2005.

104. McKenzie DC and Kalda AL: Effect of upper extremity exercise on secondary lymphedema in breast cancer patients: A pilot study. J Clin Oncol 21: 463-466, 2003.

105. Panchik D, Masco S, Zinnikas P, Hillriegel B, Lauder T, Suttmann E, Chinchilli V, McBeth M and Hermann W: Effect of exercise on breast cancer-related lymphedema: What the lymphatic surgeon needs to know. J Reconstr Microsurg 35: 37-45, 2019.

106. Keilani M, Hasenoehrl T, Neubauer M and Crevenna R: Resistance exercise and secondary lymphedema in breast cancer survivors-a systematic review. Support Care Cancer 24: 1907-1916, 2016.

107. Markkula SP, Leung N, Allen VB and Furniss D: Surgical interventions for the prevention or treatment of lymphoedema after breast cancer treatment. Cochrane Database Syst Rev 2: CD011433, 2019.

108. Cornelissen AJM, Beugels J, Ewalds L, Heuts EM, Keuter XHA, Piatkowski A, van der Hulst RRWJ and Qiu Shao SS: Effect of lymphaticovenous anastomosis in breast cancer-related lymphedema: A review of the literature. Lymphat Res Biol 16: 426-434, 2018. 
109. Winters H, Tielemans HJP, Verhulst AC, Paulus VAA, Slater NJ and Ulrich DJO: The long-term patency of lymphaticovenular anastomosis in breast cancer-related lymphedema. Ann Plast Surg 82: 196-200, 2019.

110. Granzow JW, Soderberg JM, Kaji AH and Dauphine C: Review of current surgical treatments for lymphedema. Ann Surg Oncol 21: 1195-1201, 2014.

111. Chan VS, Narushima M, Hara H, Yamamoto T, Mihara M, Iida $\mathrm{T}$ and Koshima I: Local anesthesia for lymphaticovenular anastomosis. Ann Plast Surg 72: 180-183, 2014.

112. Boccardo F, Casabona F, De Cian F, Friedman D, Murelli F, Puglisi M, Campisi CC, Molinari L, Spinaci S, Dessalvi S and Campisi $\mathrm{C}$ : Lymphatic microsurgical preventing healing approach (LYMPHA) for primary surgical prevention of breast cancer-related lymphedema: Over 4 years follow-up. Microsurgery 34: 421-424, 2014.

113. Boccardo F, Casabona F, De Cian F, Friedman D, Villa G, Bogliolo S, Ferrero S, Murelli F and Campisi C: Lymphedema microsurgical preventive healing approach: A new technique for primary prevention of arm lymphedema after mastectomy. Ann Surg Oncol 16: 703-708, 2009.

114. Ozmen T, Lazaro M, Zhou Y, Vinyard A and Avisar E: Evaluation of simplified lymphatic microsurgical preventing healing approach (S-LYMPHA) for the prevention of breast cancer-related clinical lymphedema after axillary lymph node dissection. Ann Surg 270: 1156-1160, 2019.

115. Khan AA, Hernan I, Adamthwaite JA and Ramsey KWD Feasibility study of combined dynamic imaging and lymphaticovenous anastomosis surgery for breast cancer-related lymphoedema. Br J Surg 106: 100-110, 2019.

116. Seki Y, Kajikawa A, Yamamoto T, Takeuchi T, Terashima T and Kurogi N: The dynamic-lymphaticovenular anastomosis method for breast cancer treatment-related lymphedema: Creation of functional lymphaticovenular anastomoses with use of preoperative dynamic ultrasonography. J Plast Reconstr Aesthet Surg 72: 62-70, 2019.

117. Pappalardo M, Patel K and Cheng MH: Vascularized lymph node transfer for treatment of extremity lymphedema: An overview of current controversies regarding donor sites, recipient sites and outcomes. J Surg Oncol 117: 1420-1431, 2018.

118. Liu HL, Pang SY and Lee CC: Donor limb assessment after vascularized groin lymph node transfer for the treatment of breast cancer-related lymphedema: Clinical and lymphoscintigraphy findings. J Plast Reconstr Aesthet Surg 72: 216-224, 2019

119. Brorson $\mathrm{H}$ and Svensson $\mathrm{H}$ : Liposuction combined with controlled compression therapy reduces arm lymphedema more effectively than controlled compression therapy alone. Plast Reconstr Surg 102: 1058-1067; discussion 1068, 1998.

120. Brorson H and Svensson H: Complete reduction of lymphoedema of the arm by liposuction after breast cancer. Scand J Plast Reconstr Surg Hand Surg 31: 137-143, 1997.

121. Brorson H OK, Olsson G and Svensson B: Liposuction of postmastectomy arm lymphedema completely removes excess volume: A thirteen-year study (Quad erat demonstrandum). Eur J Lymphol 17: 9, 2007.

122. Brorson H, Svensson H, Norrgren $\mathrm{K}$ and Thorsson $\mathrm{O}$ Liposuction reduces arm lymphedema without significantly altering the already impaired lymph transport. Lymphology 31 : 156-172, 1998.

123. Brorson H: Liposuction in lymphedema treatment. J Reconstr Microsurg 32: 56-65, 2016.

124. Lamprou DA, Voesten HG, Damstra RJ and Wikkeling OR: Circumferential suction-assisted lipectomy in the treatment of primary and secondary end-stage lymphoedema of the leg. Br J Surg 104: 84-89, 2017.

125. Damstra RJ, Voesten HG, Klinkert $\mathrm{P}$ and Brorson $\mathrm{H}$ Circumferential suction-assisted lipectomy for lymphoedema after surgery for breast cancer. Br J Surg 96: 859-864, 2009.

126. Schaverien MV, Munro KJ, Baker PA and Munnoch DA: Liposuction for chronic lymphoedema of the upper limb: 5 Years of experience. J Plast Reconstr Aesthet Surg 65: 935-942, 2012.
127. Brorson $\mathrm{H}$ : Complete reduction of arm lymphedema following breast cancer - A prospective twenty-one years' study. Plast Reconstructive Surg 136 (4 Suppl): S134-S135, 2015.

128. Boyages J, Kastanias K, Koelmeyer LA, Winch CJ, Lam TC, Sherman KA, Munnoch DA, Brorson H, Ngo QD, Heydon-White A, et al: Liposuction for advanced lymphedema: A multidisciplinary approach for complete reduction of arm and leg swelling. Ann Surg Oncol 22 (Suppl 3): S1263-S1270, 2015.

129. Brorson $\mathrm{H}$ and Svensson $\mathrm{H}$ : Skin blood flow of the lymphedematous arm before and after liposuction. Lymphology 30: 165-172, 1997.

130. Frick A, Hoffmann JN, Baumeister RG and Putz R: Liposuction technique and lymphatic lesions in lower legs: Anatomic study to reduce risks. Plast Reconstr Surg 103: 1868-1873; discussion 1874-1875, 1999.

131. Lee D, Piller N, Hoffner M, Manjer J and Brorson H: Liposuction of postmastectomy arm lymphedema decreases the incidence of erysipelas. Lymphology 49: 85-92, 2016.

132. Schaverien MV, Munnoch DA and Brorson H: Liposuction treatment of lymphedema. Semin Plast Surg 32: 42-47, 2018

133. Alitalo K: The lymphatic vasculature in disease. Nat Med 17: 1371-1380, 2011.

134. Karkkainen MJ, Saaristo A, Jussila L, Karila KA, Lawrence EC, Pajusola K, Bueler H, Eichmann A, Kauppinen R, Kettunen MI, et al: A model for gene therapy of human hereditary lymphedema. Proc Natl Acad Sci U S A 98: 12677-12682, 2001.

135. Kriederman BM, Myloyde TL, Witte MH, Dagenais SL, Witte CL, Rennels M, Bernas MJ, Lynch MT, Erickson RP, Caulder MS, et al: FOXC2 haploinsufficient mice are a model for human autosomal dominant lymphedema-distichiasis syndrome. Hum Mol Genet 12: 1179-1185, 2003.

136. Norrmen C, Tammela T, Petrova TV and Alitalo K: Biological basis of therapeutic lymphangiogenesis. Circulation 123: 1335-1351, 2011.

137. Tammela T, Saaristo A, Holopainen T, Lyytikkä J, Kotronen A, Pitkonen M, Abo-Ramadan U, Ylä-Herttuala S, Petrova TV and Alitalo K: Therapeutic differentiation and maturation of lymphatic vessels after lymph node dissection and transplantation. Nat Med 13: 1458-1466, 2007.

138. Lahteenvuo M,Honkonen K, Tervala T, Tammela T, Suominen E, Lähteenvuo J, Kholová I, Alitalo K, Ylä-Herttuala S and Saaristo A: Growth factor therapy and autologous lymph node transfer in lymphedema. Circulation 123: 613-620, 2011.

139. Shimizu Y, Shibata R, i Shintani S, Ishii M and Murohara T: Therapeutic lymphangiogenesis with implantation of adipose-derived regenerative cells. J Am Heart Assoc 1: e000877, 2012.

140. Conrad C, Niess H, Huss R, Huber S, von Luettichau I, Nelson PJ, Ott HC, Jauch KW and Bruns CJ: Multipotent mesenchymal stem cells acquire a lymphendothelial phenotype and enhance lymphatic regeneration in vivo. Circulation 119: 281-289, 2009.

141. Hwang JH, Kim IG, Lee JY, Piao S, Lee DS, Lee TS, Ra JC and Lee JY: Therapeutic lymphangiogenesis using stem cell and VEGF-C hydrogel. Biomaterials 32: 4415-4423, 2011.

142. Toyserkani NM, Jensen CH, Andersen DC, Sheikh SP and Sørensen JA: Treatment of breast cancer-related lymphedema with adipose-derived regenerative cells and fat grafts: A feasibility and safety study. Stem Cells Transl Med 6: 1666-1672, 2017.

143. Toyserkani NM, Jensen CH, Tabatabaeifar S, Jørgensen MG, Hvidsten S, Simonsen JA, Andersen DC, Sheikh SP and Sørensen JA: Adipose-derived regenerative cells and fat grafting for treating breast cancer-related lymphedema: Lymphoscintigraphic evaluation with 1 year of follow-up. J Plast Reconstr Aesthet Surg 72: 71-77, 2019.

This work is licensed under a Creative Commons Attribution-NonCommercial-NoDerivatives 4.0 International (CC BY-NC-ND 4.0) License. 